\title{
Vidros partidos (2012), de Víctor Erice: Una poética del montaje
}

\author{
Jesús Ramé López \\ Universidad Rey Juan Carlos (URJC), Departamento de Sociología y Comunicación \\ jesus.rame@urjc.es \\ https://orcid.org/0000-0002-7480-949X
}

RESUMEN Vidros partidos es un cortometraje dirigido por Víctor Erice que se integra en la película de producción portuguesa Centro histórico (2012). A este proyecto (producido por Guimarães 2012, Capital Europea de la Cultura) se sumaban en su realización los directores Pedro Costa, Manoel de Oliveira y Aki Kaurismäki, con respectivos cortometrajes propios. El film se desarrolla en un fabrica del norte de Portugal y parte de una fotografía de trabajadores y trabajadoras que cuelga de una pared del comedor de la misma. Se compone de diferentes entrevistas a personas que tuvieron alguna relación con la fábrica y que nos muestran un contexto de producción que el capitalismo cognitivo ha hecho desaparecer. Sin embargo, el guion está firmado por el autor e interviene un actor profesional, con lo cual todo el aspecto documental se viene abajo y la verdad de la película hay que encontrarla en otro espacio de la obra, entre la ficción y el documental. Todo esto es acompañado por una propuesta de montaje que trata de desgranar los secretos que pueda entrañar la fotografía que da motivo a la película. Desde la estética de los materiales, investigaremos cuál es el gesto creativo de montaje en el proceso creativo que cristaliza en una textura fílmica. Nos centraremos en los modos de relación que se generan entre los materiales organizados en unidades tonales en sus diferentes partes para, de este modo, crear una unidad total de discurso. El montaje de Vidros partidos, tras la precisa escritura del guion y la filmación, conllevan, en términos de Lukács, una re-antropomorfización puesta en juego por el ritmo fílmico, el cual deja un rastro de su génesis artística y expresa una poética que hace emerger una explicación sobre el paso del capitalismo industrial al capitalismo cognitivo.

PAlabRas Clave Estética fílmica; teoría del montaje; documental; Víctor Erice; materialidades; procesos creativos.

\section{Un director español, una película portuguesa}

Vidros partidos. Testes para um filme em Portugal es el capítulo dirigido por Víctor Erice en la película colectiva Centro Histórico en 2012. Esta obra fílmica estaba completada por las partes dirigidas por Pedro Costa, 
Manoel de Oliveira y Aki Kaurismäki, cuyos títulos eran, respectivamente, Sweet Exorcism, O Conquistador, Conquistado y $O$ Tasqueiro. Es importante destacar que, aunque tiene como directores a dos creadores no portugueses, la película es de producción portuguesa, financiada por Guimarães 2012, Capital Europea de la Cultura. A partir de la idea de utilizar la ciudad de Guimarães, en esta obra se intenta dar una respuesta fílmica al significado de la memoria. Cada uno de los directores da una visión ajustada a su forma de ver el cine, pero la pieza de Erice es especial porque se construye desde la mirada de alguien ajeno a esta parte de Portugal, un extraño que busca y que crea desde un hecho local, como es una fábrica abandonada, una cristalización del cambio que han traído los nuevos modos de hacer en la producción de mercancías.

Vidros partidos es una producción realizada con un actor profesional y «entrevistados» portugueses, rodada en Portugal y en la lengua portuguesa, por lo que podemos decir que es una película totalmente lusa. Explica el desarrollo histórico de una fábrica de tejidos de Río Vizela, fundada a finales del siglo XIX y que fue una de las mayores factorías de tejidos de Europa. Hace un perfecto análisis de la recesión económica que provocó la inmersión en el capitalismo cognitivo y la desaparición del capitalismo industrial, heredado del capitalismo mercantil (Broncano 2019, 57). La escenificación de esta transformación se produce en los modos de producción a través de un caso de carácter local, una fábrica que hasta su cierre fue centro neurálgico de las prácticas cotidianas de sus empleados.

Aunque esta obra forme parte de una película coral, la podemos considerar como una pieza artística independiente en un formato de mediometraje (37 minutos). Su calidad y complejidad estética, no exhibicionista, la convierten en objeto de estudio para el análisis del montaje dentro de una investigación de las materialidades fílmicas y sus modos de relación traducidos en poéticas.

\section{Unas condiciones especiales de antropomorfización para una poética del montaje}

Si partimos de una estética para el cine, desde la idea de Lukács de que cristaliza a base de relaciones, podemos decir que se dan diferentes antropomorfizaciones que desembocarían en una última reantropomorfización que es el montaje (Lukács 2019b, 74). Los 
procesos de antropomorfización fílmica - guion, realización y montaje en el cine de los oficios se producen en la relación que emerge entre las materialidades de los diferentes momentos del proceso creativo, propiciando un "modo de relación" (Claramonte 2016, 24).

Cuando hablamos de antropomorfización nos referimos a esa particularidad del arte para filtrar el mundo a través de la mirada del ser humano, desplegando esta visión en prácticas u obras artísticas. La peculiaridad del cine es que en su reflejo de la realidad existen momentos de desantropomorfización, porque la filmación puede convertirse en una visión nueva que puede dar un valor científico a la imagen. Podemos pensar en el ralentizado del vuelo de una abeja o el marchitar de una flor a cámara rápida; las dos imágenes nos dan información sobre cómo funciona la realidad, pero también pueden usarse, a través del montaje, con un sentido narrativo, poético o discursivo.

Entendemos el cine de los oficios como una práctica operacional de diferentes creatividades, ya sean la escritura del guion, las profesiones que intervienen en un rodaje - arte, diseño o estilismos - y las aportaciones en el resultado final de los diferentes trabajadores de la postproducción. Todas estas creatividades en dialéctica trabajan con diferentes materialidades y diferentes niveles de desarrollo de la obra fílmica. Esta es una peculiaridad del cine que no siempre se destaca lo suficiente. En esta ocasión, nos centraremos en el montaje, ya que tiene la particularidad de ser pensado desde el inicio de la creación, pero dirige nuestra investigación hasta una textura fílmica final. Entendiendo la textura artística, en una relectura para el cine de Giuliana Bruno, como el "paisaje de la superficie" (Bruno 2014, 15) que emerge en la experiencia estética, y, en el caso del cine, que coincide con lo que sucede en la pantalla. La poética puede, así, ser descrita como la emergencia de una superficie, pero no superficial, sino puesta en juego desde la materialidad de la textura cinematográfica en el montaje: los cuerpos, objetos y sonidos que acontecen en cada plano.

En la última re-antropomorfización que desarrolla el montaje se despliegan algunos componentes que nos ayudarán a lograr definir la poética que se ha elegido en la película. En todo momento, como estará observando el lector, estamos recurriendo a una poética de la materialidad fílmica, por lo tanto, no podemos dejar de nombrar la influencia de António Reis y Margarida Cordeiro en el análisis del corte cinematográfico y el tiempo interno del plano. Partimos de una 
aproximación visual al objeto filmado desde el sujeto que filma, que después se resolverá en las decisiones de montaje y que pondrán en relación las materialidades, en una suerte de "estética de los materiales" (Cucinotta 2018, 263). Esto conecta algunas prácticas fílmicas que podemos ver reflejadas en los modos de hacer bressonianos para la creación, sombra que se alarga en el transcurso de Vidros partidos y que se ve reflejada en el montaje: "montar una película es enlazar las personas unas con otras y con los objetos a través de las miradas" (Bresson 1997, 22).

Esto se completa con la categoría de "modo de relación" de estas materialidades que supone el medio homogéneo del cine en el momento de su fase final en la edición (Claramonte 2016, 24). De este modo recogemos como método la búsqueda en las poéticas de un repertorio de elementos (materialidades) y unas disposiciones para ponerlos en relación. Ya hemos visto el tratamiento del montaje como la creación de texturas articuladas por su materialidad recogida por Bruno, pero no debemos olvidar la intención de partir de una génesis creativa de los materiales, de los rastros de la creación, que nos haga entender la obra y que recoge el sentido de la crítica genética. En este caso recurriremos al estudio de la apariencia de una obra en curso, como explica Cecilia Salles $(1998,26)$, pero en un sentido inverso, donde los gestos preparativos de la producción audiovisual toman una estética de lo inacabado en el resultado final. Los planteamientos de Salles pueden completarse con la idea de análisis de creación en el sentido de Alain Bergala (2007, 127), donde recorremos la obra, cual detectives, reconociendo las estrategias de montaje y los gestos creativos.

En este caso, aunque vayamos a analizar el montaje, es necesario explicar el proceso creativo en sus diferentes antropomorfizaciones, ya que afectan a la definición de una poética. Debe quedar claro que entendemos montaje en una "definición amplia", como "principio que regula la organización de los elementos fílmicos visuales y sonoros" (Aumont, Bergala, Marie y Vernet 1996, 62), no como una práctica fuera del ámbito creativo.

Esta película empieza con los protagonistas de la desaparición de la fábrica, los trabajadores y trabajadoras, siendo «entrevistados» para, a continuación, escribir un guion y dárselo a esos mismos protagonistas para que lo interpreten. Al mismo tiempo, se eligió a un actor para una de las intervenciones. Hemos puesto "entrevistados" entrecomillado, 
por esta suerte de interpretación compartida, por este pacto entre el creador y los trabajadores y trabajadoras que aparecen en imagen. En este sentido ya hay una idea de edición en la escritura, porque los diálogos se ajustan a una estructura concreta. De este modo se definen los materiales del discurso en el proceso de creación, que serán los cuerpos de los trabajadores puestos en la fábrica como contexto y el sonido de sus palabras explicándose. Además, juega con la idea de hacer desaparecer esa idea tradicional que separa a la ficción y el documental en dos compartimentos estancos.

Los personajes van a ir interactuando con una fotografía colocada tras ellos, cuyo modo de relación se entenderá mejor con el análisis del montaje, pero que ya despliegan en el rodaje desde la relación entre los diferentes cuerpos, objetos y sonidos. Esto nos lleva a lo que José Luis Guerín denomina como "puesta en mirada" y que vuelve a señalar la desenfocada frontera entre ficción y documental, ya que el creador tiene un reto ante sí y está obligado a hacer un "ejercicio de mirada" (Armador 2019). En este caso, la puesta en escena intenta dirigir la contingencia propia del cine hacia un lugar intermedio entre una observación de autor con carácter de escritura y una obra colectiva. De este modo, asistimos a una liturgia creativa que produce una representación secular sagrada, la cual puede ser denominada como "cine de no ficción".

\section{Materialidades puestas en relación como elemento de análisis del montaje}

Cuando hablamos de poéticas, las entendemos, en un sentido clásico, como «modos de hacer», con sus repertorios y sus disposiciones concretas, donde entra en juego lo necesario y lo posible - en dialéctica con lo contingente y lo imposible - para el hecho artístico que cristaliza en una efectividad (Claramonte 2016, 23). Estas formas de crear en el cine siguen una pauta poética performativa, poiein, definida por unas prácticas y unos medios concretos (Arendt 2005, 189), los cuales tienen unos materiales específicos en sus diferentes antropomorfizaciones.

Vidros partidos parece definirse en un gesto improvisado, ya que el subtítulo de la película, Testes para um filme em Portugal, nos invita a pensar que lo que vamos a ver son las pruebas, el boceto, para otra película. Además, los títulos que anuncian cada parte se relacionan con 
una fecha, elemento este que estructura y le da un carácter de obra en curso. Pero, realmente, si tenemos que definir la película desde un análisis del montaje, y sabiendo el proceso creativo que se ha realizado, descubrimos que su estructura está definida como una conversación con una fotografía. Esta fotografía fue encontrada por Erice en una estancia de la fábrica y representa a los trabajadores en un comedor (Imagen 1). Lo interesante es ver que hay una cierta conciencia de los comensales en el hecho de que se estaba haciendo la fotografía, lo cual da una expresión especial a sus gestos.

Para percibir mejor esta idea, vamos a pararnos en cada una de las partes, que tienen su propia unidad tonal y que construyen una tonalidad emocional total (Lukács 2019a, 191) para su entendimiento. Esta idea podría resumirse en la afirmación de uno de sus personajes cuando explica lo que le provocan los cuerpos de la fotografía: "parece que quieren decir algo, pero no sé bien lo que es" (26m40s).

Vidros partidos está dividida en diferentes partes que tienen sus propios títulos de inicio y que definen lo que vamos a ver, aunque está precedida por una introducción en la cual se presenta el contexto, la fábrica en su materialidad de abandono, en el que se van a realizar las entrevistas y se presenta la fotografía en su entorno. Aquí ya se definen los diferentes estratos verticales, en los que se colocarán los cuerpos para desplegar sus discursos, y las articulaciones horizontales entre planos. Estas relaciones verticales y horizontales entre materiales de montaje conformarán en cada parte una textura fílmica de influencia mutua.

Analizaremos la poética de cada bloque según una conversación con el pasado a través de su interlocutor, la fotografía. De hecho, veremos cómo en cada parte se da un modo de relación con dicha imagen. En este sentido serán importantes tanto los choques entre los estratos de la imagen como las estrategias de montaje entre planos en la creación de una textura tonal. Para un mejor entendimiento del análisis, hemos dividido la película en seis bloques, que corresponden a otras tantas unidades tonales que definen los diferentes diálogos con la fotografía:(1) La introducción, (2) "7 de mayo. Pruebas de hombres y mujeres", (3) "8 de mayo. La fotografía", (4) "9 de mayo. Pruebas Valdemar Santos", (5) "10 de mayo. Pruebas acordeonista" y(6) Epílogo final. 


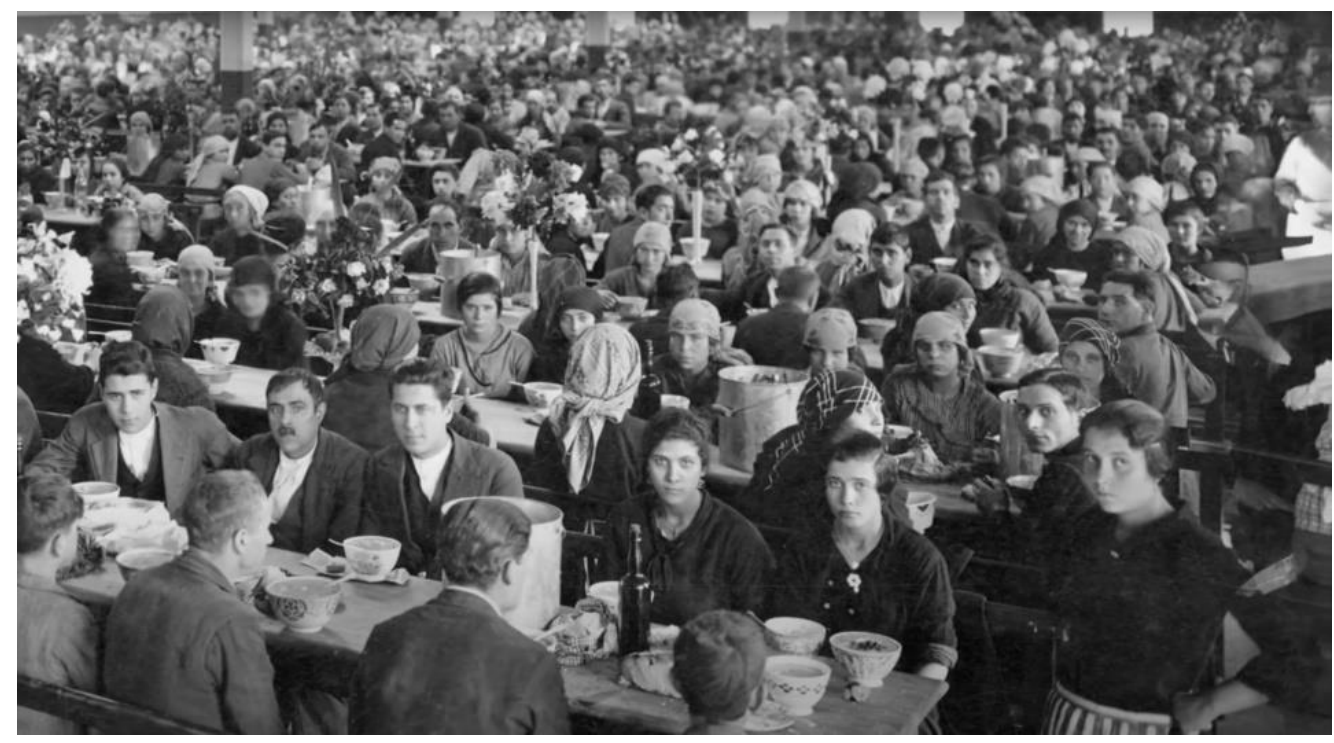

Imagen 1: Fotografía del comedor con los obreros analizada en este documental. Fotograma de la película. Vidros partidos. Testes para um filme em Portugal, de Victor Erice (33m51s). | (c) Guimarães 2012, Capital Europea de la Cultura.

\section{Poética del montaje en Vidros Partidos}

La primera imagen de la película, que aparece sobre un sonido de goteo, es un mural de cerámica que representa a unos hombres y mujeres vestidos como campesinos, pero el centro es dominado por unos tejidos que dejan al fondo una fábrica. Esta textura de montaje estático nos da la pista de los elementos que va a utilizar la película para explicar el cambio histórico, pero, además, sobre ella unos títulos explican que la fábrica se fundó en 1845 y que en 2002 se cerró. El título de la película se ha colocado sobre una imagen de la fábrica vacía, para, así, dar desde el principio un aspecto estético de work in progress.

El montaje se basa, fundamentalmente, en el estrato de la tridimensionalidad y destaca un objeto, la fotografía, que se va iluminando poco a poco, descubriendo también el espacio de un comedor. Sobre el sonido de unas campanas, la fotografía se muestra con más detalle. Ya sabemos por los títulos que la llaman "la fábrica de los cristales rotos" y que nos centramos en el antiguo comedor, por lo tanto, es un espacio deshabitado que va a ser narrado. Su unidad tonal está constituida por la incertidumbre frente a la historia y el repertorio 
de materialidades son planos fijos de la fábrica y los recortes sobre la fotografía encadenados.

Tras la introducción volvemos de nuevo al espacio del comedor encuadrado con la fotografía al fondo, un título lo anuncia: “7 de mayo. Pruebas de hombres y mujeres". Después suena como cantan y cierran una claqueta, al mismo tiempo que la cámara hace un ligero movimiento de encuadre, en un efecto de distanciamiento y, para mostrar el gesto creador, nos devuelve a los mecanismos de las pruebas de rodaje. Este capítulo es el más largo y ocupa más de la mitad del metraje, siendo el que articule el discurso y sobre el que pivotan las otras. Incluso las imágenes que vimos en la introducción toman un nuevo valor con las declaraciones que se desplegarán a continuación. Fundamentalmente la planificación se formulará en un primer plano y otro americano por cada uno de los personajes, sentados estos siempre de espaldas a la fotografía. El esquema se repite y en casi todas las declaraciones aparece el plano largo y pasa en un momento dado al corto. Los personajes siempre se presentan y dicen su edad, como si estuvieran en un casting. Además, los parlamentos están separados por fundidos en negro, dando un aspecto de ordenamiento casual para un posible visionado. Sin embargo, en un análisis en detalle nos damos cuenta de que el discurso está más medido de lo que parece. Para una mejor comprensión de lo que aporta cada personaje dentro de esta parte de la película, vamos a destacar los elementos del discurso de cada uno con la intención de explicar el carácter global de este bloque. Descubriremos cómo cada uno de ellos aporta una narración sobre la peculiaridad de la fábrica, la situación de la clase trabajadora industrial y la relación con la fotografía.

Amândio Martins es el que inicia la oralidad, relatando su vida y su condición de operador en la fábrica. Lo maravilloso de su parlamento es que con doce años decide pedir trabajo ofreciendo sus manos como herramientas. Esto nos remite al capitalismo industrial que entiende al ser humano como mano de obra, como instrumento. El montaje, dentro de una excepción de estilo, pasa a sus manos, su cuerpo, y nos relata todas las lesiones que se produjeron en ellas al trabajar en la fábrica. Una explicación del hombre como ampliación de la máquina. Aquí los estratos funcionan a través de las manos (Imagen 2) y el sonido de la palabra, que provoca una visión del cuerpo, unas emociones por la narración, pero también un contacto con el pasado y una posibilidad de análisis de la historia desde el presente. El gesto creativo de mostrar las 
manos se funde con el gesto del trabajo, imaginado, a través del cuerpo del presente.

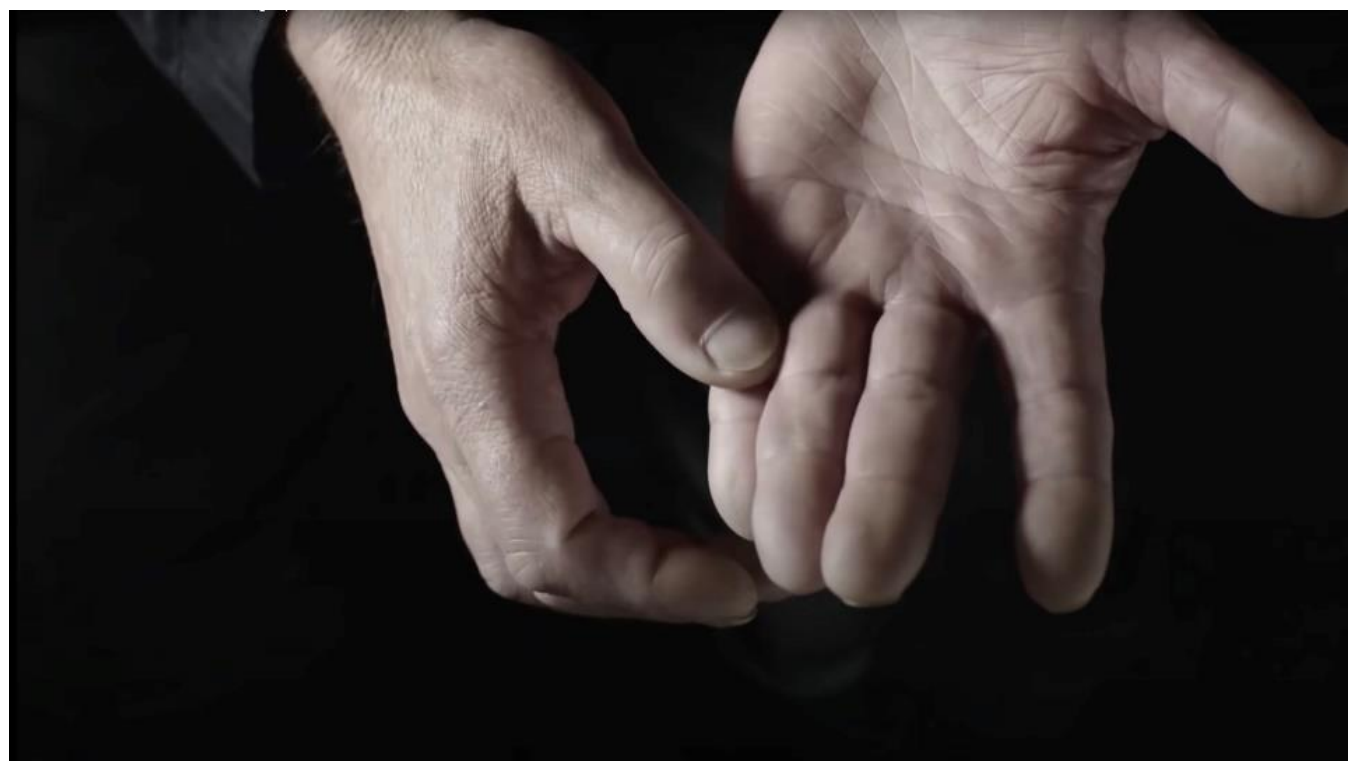

Imagen 2: Detalle de las manos de un obrero de la fábrica. Fotograma de la película Vidros partidos. Testes para um filme em Portugal, de Victor Erice (05m06s). | ( ) Guimarães 2012, Capital Europea de la Cultura.

Si antes Amândio Martins había desplegado los modos de hacer y consecuencias en el cuerpo del ser humano como herramienta, ahora María de Fátima habla de la familia como núcleo de crianza con relación al trabajo. Se refiere a la foto porque su padre trajo una de las mesas que aparecen en ella a su casa para no tener que comer en el suelo. Se ofrece una conversación con la fotografía, ya que incluso habla del comedor como un lugar de encuentro con la lactancia de las trabajadoras. Además, conecta con la memoria recordando un dicho de su abuela que explica el mundo como una rueda: "Por mucho que la gente quiera, ella nunca rueda para ti, acabo de contar retales de una historia, lo que yo tengo almacenado dentro de mi memoria" (08m40s). Este relato nos emociona, pero también nos remite al mundo de los cuidados, ese trabajo que no se ve y que no se paga, una tradición que ha sido heredada por el capitalismo actual, donde sigue recayendo mayoritariamente en la mujer.

El siguiente personaje es Rosa Gonçalves, quien representa a esa generación que venía de familia campesina y que se convierte en una de las primeras trabajadoras industriales de la región. Ella debía 
amamantar a su hija durante el trabajo, lo cual se convertía en una situación muy dura y en un reflejo de lo que Foucault llama biopolítica, cómo afectan a nuestra vida cotidiana las relaciones de poder, es decir, "racionalizar los problemas planteados a la práctica gubernamental ${ }^{1}$ por los fenómenos propios de un conjunto de seres vivos constituidos como población: salud, higiene, natalidad..." (Foucault 2007, 359).

El siguiente es Manuel Silva, que da una visión teológica del trabajo, pensando que Dios da y el trabajador acepta. Esta intervención aporta la dimensión religiosa, resignada, de una sociedad conservadora en la que se instala el capitalismo industrial. Esta estructura tradicional se conserva en parte hasta la actualidad y deja su huella en las personas.

Maria Ana Coutinho Serrão, es el ejemplo de la mujer que se construye a sí misma en un mundo de cambios y machista. El relato muestra una anécdota reveladora, cuando explica que dejó en el altar a su prometido porque le había mentido en cuanto a sus posesiones. Esto recuerda una sociedad donde el matrimonio tenía un significado más conservador que en la actualidad, evocando la fotografía en esos grupos en los que aparecen lo que se asemeja a posibles parejas. También ella dejó la fábrica y se fue a Francia, representando a la población portuguesa que emigró buscando un mundo mejor, tan propio del capitalismo industrial.

El siguiente personaje es Judite Araújo, lo cual suma una mujer más, situación que ya adelantaba la fotografía, porque muestra que había un alto número de mujeres trabajando en esta fábrica. Con ella se plantea el problema de las enfermedades laborales a través la lesión del oído que le causó el ruido de las máquinas. Es un ejemplo de cómo la industria traía consigo nuevas patologías y de cómo estas enfermedades debían aceptarse si no querías ser despedido. En este caso dando como resultado un trasplante y una resignación económica, que no religiosa. La fotografía será vista ahora también desde las patologías que producía la fábrica. El espectador más atento, después, descubrirá las orejas cubiertas bajo los pañuelos de la mayoría de las trabajadoras.

Miguel Viana da Silva completa la historia del pueblo portugués de los años 70, porque narra su marcha a la guerra de Mozambique, elemento fundamental para la clase trabajadora de este país. Explica los cambios

${ }^{1}$ Práctica gubernamental, entendido como relación de poder sobre un colectivo. 
de manejo de una máquina, inicialmente por diez personas, para pasar a hacerlo una sola. Además, cuenta como en los años 90 los trabajadores de Indonesia o Camboya recibían mucho menos sueldo que los ya precarios salarios de Portugal. Esta mano de obra barata provocó muchos despidos en la Europa industrial y la consecuente subida del paro y desorientación de unos trabajadores que habían dedicado toda su vida a la fábrica. La fotografía ahora tendrá un peso melancólico, sabiendo que muchas de las personas que aparecen en ella serán despedidos.

El siguiente es António Monteiro Bastos, que, tras trabajar en la fábrica, partió a Francia en 1956, formando una familia en este país y llegando a ser un trabajador fijo en la Renault. Al final volvió a su casa por la saudade de su tierra. Este personaje habla de la emigración, pero también de cómo los modos de producción ya no crean los empleos de antes y la manufactura se desplaza a Asía, dejando un futuro de trabajo esclavo, en el que sus nietos ocupan un lugar incierto. La fotografía ya es el pasado y queda claro que ya no se repetirá una situación similar en el capitalismo cognitivo.

Para finalizar este bloque es entrevistada Inês Ferreira Gomes, que es la persona de mayor edad de todos los personajes. Es muy interesante cómo define a la fábrica como una máquina total, donde hay algunos componentes que piensan, los seres humanos. Las personas como herramientas que piensan durante el trabajo, por ejemplo, en "los viajes que le gustaría hacer si le tocara la lotería” (20m43s). Refleja la idea de la imposibilidad de la felicidad cuando el contexto solo te permite pequeños momentos de alegría. Una mujer soñadora que no puede realizar todos sus planes y que queda, como ella dice, en la "alegría del descontento", definición que escribió su prima y ella recuerda (22m58s). La fotografía ahora nos muestra que entre las miradas hay miradas soñadoras que no pudieron realizar sus proyectos, atrapados en el contexto de un norte de Portugal entregado a los modos de producción industrial. La pequeña vida cotidiana de Inês refleja la apropiación de los cuerpos, su sensibilidad y sus deseos por la conversión del ser humano en fuerza de trabajo.

El montaje resalta la diferencia entre las personas que hablan y a quienes se refieren, que, aun siendo ellos mismos - lo cual no siempre está claro por el esquema creativo utilizado - son personas distintas por no compartir el contexto. En este sentido, a través del montaje en Vidros partidos se encuentran dos mundos y, como explica Villarmea, 
en esta película "se hace eco de la actual desorientación de la clase trabajadora, que ha perdido su agenciación como consecuencia de su incapacidad para hacer frente al cierre y deslocalización de las fábricas" (Villarmea 2020, 153).

Aquí acaba esta primera relación de los cuerpos, sus sonidos, discursos y el espacio donde reposa la fotografía (comedor). Una relación que no es clásica, ya que el objeto que sobrevuela las entrevistas está detrás de los personajes y ellos no lo ven. La fotografía preside todos los discursos y es interpelada directamente por algunos gestos de los "entrevistados" que la señalan, pero hay una referencia a ella que se crea en el espectador, observador que va descubriendo un valor nuevo en la mirada de los trabajadores. Poco a poco se construye un estudio sobre la memoria que contendrá la fotografía cuando acabemos el visionado de la película.

Las materialidades se ven claramente estratificadas por los términos en que se han definido los encuadres de las entrevistas. La trama audiovisual que se crea está organizada por los aspectos que van añadiendo los «entrevistados». Emerge una unidad tonal, una textura, que articula diferentes elementos que los trabajadores ven relevantes en sus vidas personales, pero que dan una visión general del modo de producción de la época industrial en sus aspectos de contexto político/histórico/social: la familia, la emigración, la alienación del ser humano/herramienta, el cambio de los medios de producción. Al mismo tiempo, la edad de los participantes evoca la época acabada de los protagonistas de la fotografía, donde todo el mundo empezaba a trabajar muy joven, con 12 o 14 años.

El siguiente bloque, que nosotros hemos definido como «el rostro y el discurso/fotografía», desde la relación de los cuerpos con el objeto, empieza con el título "8 de mayo. La fotografía”. Al basarse en la mirada de los personajes, vemos claramente un planteamiento rítmico de montaje bressoniano: "Conmover, no con imágenes conmovedoras sino con relaciones entre imágenes que las vuelven a la vez vivas y conmovedoras" (Bresson 1997, 70). Mientras se escribe el título se vuelve a oír cómo se canta la claqueta y su clack, siendo este ya un sonido recurrente. En este inicio se va a utilizar el esquema de montaje plano/contraplano clásico, pero sobre el propio eje de la cámara. A partir de un plano general de Amândio de espaldas mirando a la fotografía cortaremos a los rostros de los personajes, donde estos se van a referir directamente a la imagen porque ahora la miran siendo 
interpelados por ella, sin embargo, el espectador ahora no ve la fotografía. Antes estaba presente, pero no era una interpelación directa, ahora los personajes se referirán a ella, creando una imagen en el espectador desde el fuera de campo. Por el parecer de los «entrevistados» $\mathrm{y}$ las sensaciones que provocan sus miradas, entendemos un modo de producción. Martins, por ejemplo, habla de la jornada laboral de lunes a viernes y de los sentimientos encontrados de los trabajadores y trabajadoras: tristeza por la dureza y felicidad por no estar desempleados. El resto de los personajes - los únicos que no aparecen son Manuel y Miguel - subrayan de forma concisa la tarea miserable, la explotación y alienación de los rostros de la fotografía. Algunos no reconocen a la gente, pero además no reconocen al tipo de trabajador en la actualidad, explicando un cambio antropológico en los modos de hacer cotidianos. Hay una cierta incomprensión de los rostros que ven, donde algunos ven dignidad otros ven miseria, pero Inês expresa claramente su incomprensión al manifestar, como anticipamos antes, el desconocimiento de lo que quieren transmitir las miradas reflejadas por la fotografía (Imagen 3 ).

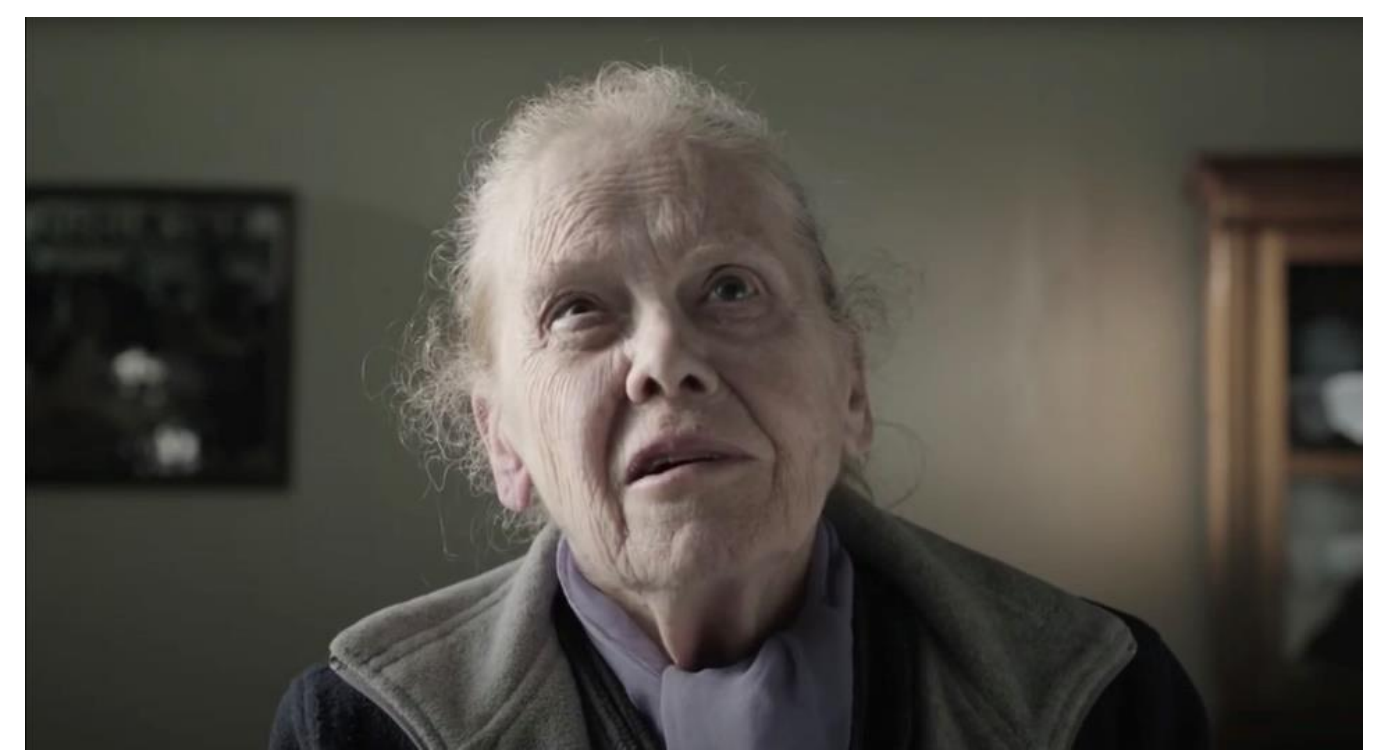

Imagen 3: Inês mira la fotografía desde su incomprensión. Fotograma de la película Vidros partidos. Testes para um filme em Portugal, de Victor Erice (26m24s). | ( Guimarães 2012, Capital Europea de la Cultura.

En este bloque la materialidad tiene la particularidad de enfocarse en lo ausente, esa fotografía que interpela fuera del encuadre. La fotografía solo aparece al principio y al final, y el peso del montaje se da a la 
expresión y la palabra en primer plano - cuerpo y sonido. Estos planos están recogidos con la cámara un poco más debajo de la cara, con el fin de acentuar la mirada hacia el objeto de interpretación, que está sobre sus cabezas. La estructura de montaje rompe con la idea inicial de conversación clásica y deja al espectador elucubrar y construir la imagen que ven los "entrevistados". Todos tienen un aire de melancolía al mismo tiempo que su rostro muestra el esfuerzo puesto en el recuerdo y en la lectura de la imagen. La textura audiovisual se compone de rostros rematados por el contraplano general del inicio y del final del bloque, creando una unidad tonal en torno a la interpretación de los rostros de la fotografía y al contexto histórico y social.

La siguiente parte introduce una novedad que da un nuevo tono, una nueva textura para poner en relación con las demás, ya que es, en este caso, un actor, Valdemar Santos, el que se interpreta a sí mismo - o no ${ }^{2}$ -, quien habla de su profesión con relación a la memoria y la interpretación de Carlos Marques en El capital, obra del dramaturgo socialista Ernesto da Silva. Este autor perteneció a una corriente de teatro para la educación de los obreros y obreras que fue inaugurada con esta composición teatral (Peralta 2017, 223), remitiendo a la introducción en la película de cómo desaparecen algunos modos de hacer artísticos cuando se pierden ciertos modos de producción. De hecho, en un momento de su intervención señala la fotografía como el reflejo auténtico, en los rostros y cuerpos que aparecen, del personaje que él interpretó. El bloque empieza desde un fundido en negro y con un nuevo título, "9 de mayo. Pruebas Valdemar Santos", lo cual separa claramente esta parte de las demás. Además, se vuelve a escuchar el gesto de la creación a través del sonido de la claqueta que anuncia cada parte. Como hemos anticipado, la estructura que ahora se elige es la de confrontar una interpretación actoral con la fotografía.

Este es un momento de la película, sobre todo para el público portugués que reconoce al actor, de distanciamiento brechtiano, donde vemos la concentración del discurso en una suerte de realismo crítico lukacsiano. Valdemar Santos vuelca sus gestos, su trabajo profesional, sobre un monólogo: palabras que dan sentido a la relación entre el arte y el

\footnotetext{
${ }^{2}$ Esta película tiene la peculiaridad de no dejar nunca claro hasta qué punto lo que dicen los personajes pertenece a sus vidas. Este ejercicio de escritura cinematográfica permite que en el visionado emerja una concentración plena en lo que se dice, en la valoración del discurso por parte del que observa y escucha.
} 
trabajo. Es interesante cómo el texto no interrumpe el desarrollo narrativo, sino que lo completa, como escribe Bresson: "un raudal de palabras no perjudica una película. Cuestión de especie, no cantidad" (Bresson 1997, 32).

El actor está de pie y se sienta, con la imagen detrás, acompañado por un movimiento de cámara que lo reencuadra. El movimiento hacia la silla lo diferencia como actor, como un trabajador del cuerpo fuera de la fábrica, un trabajador cultural. De repente, sin cortes de montaje en ningún momento, Valdemar Santos se quita la chaqueta e interpreta el papel de Carlos Marques. ${ }^{3}$ El discurso explica la desigualdad del capitalismo industrial, gesto que suma una nueva perspectiva a los parlamentos de los personajes anteriores y a la contemplación de la fotografía que haremos al final, contribuyendo a una unidad tonal total. Cuando deja de interpretar nos habla del presente, de esa virtualidad que se impone y que afecta a todo el mundo, incluso al trabajo de un actor. El gesto de dejar hablar al actor sin cortes muestra el esfuerzo por una escritura cinematográfica que se apoya en la oralidad para ilustrar una realidad. No cortar en montaje también nos habla de un cine alejado de los mecanismos de producción digital, un cine de los oficios, que todavía se basa en el mundo material.

La siguiente parte empieza, tras un fundido en negro, con una persona de pie, más joven, que también se sienta acompañada por un reencuadre de la imagen y por la presencia a sus espaldas de la fotografía. Este esquema de "puesta en mirada", que nos ha acompañado durante toda la película, provoca que no nos olvidemos de la fotografía. Volvemos a escuchar la claqueta y el título anuncia una nueva forma de afrontar el tema: "10 de mayo. Pruebas acordeonista". Este bloque va a permitir relacionar la vida presente del personaje elegido, Arménio dos Santos Cruz, con la fotografía. Él nos sorprende con la afirmación de que nunca ha trabajado en esta fábrica, pero justo esto será lo que introduzca un nuevo matiz al desarrollo de la estructura fílmica, ya que su familia sí lo hizo. Representa a la primera generación que pudo estudiar y que pudo ir a la universidad. Es músico, pero un músico del capitalismo cognitivo, con estudios. Su padre en cambio tocará el acordeón formando parte de la banda de la fábrica, pero será un músico del capitalismo industrial. De nuevo el tema de la

\footnotetext{
${ }^{3}$ Nombre que evoca a Karl Marx, dibujando la mirada revolucionaria en su discurso a cámara.
} 
familia y sus modos de relación, que tanto se articula con la memoria y que ha formado parte de toda la filmografía de Erice, pensemos en $\mathrm{El}$ espíritu de la colmena (1973) o en Alumbramiento (2002).

El objeto que salvaba de la tristeza del trabajo a su padre es el sustento de su hijo. La música se convierte en la protagonista de la comunicación de la experiencia, retazos en el presente de un mundo que ya no existe, pero que queda reflejado en la siguiente parte, separada por un fundido en negro. El epílogo empieza con un acordeón sobre una silla delante de la fotografía y Armenio se acerca a él y se lo coloca, sentándose de espaldas al espectador y frente a la imagen de los trabajadores y trabajadoras (imagen 4). La puesta en mirada hace un interesante juego de montaje, ya que cortamos a un encuadre similar al de los personajes cuando miraban la foto, pero el músico no hablará, sino que empezará a tocar el acordeón. El sonido/instrumento religará el pasado con el presente a través de una práctica tradicional, la música popular, lo que relaciona la memoria y el poso del pasado en dialéctica. Ahora sí, a partir del montaje de encuadres seleccionados de la fotografía con diferentes grupos de trabajadores, vemos en detalle a los trabajadores y trabajadoras de la fotografía.

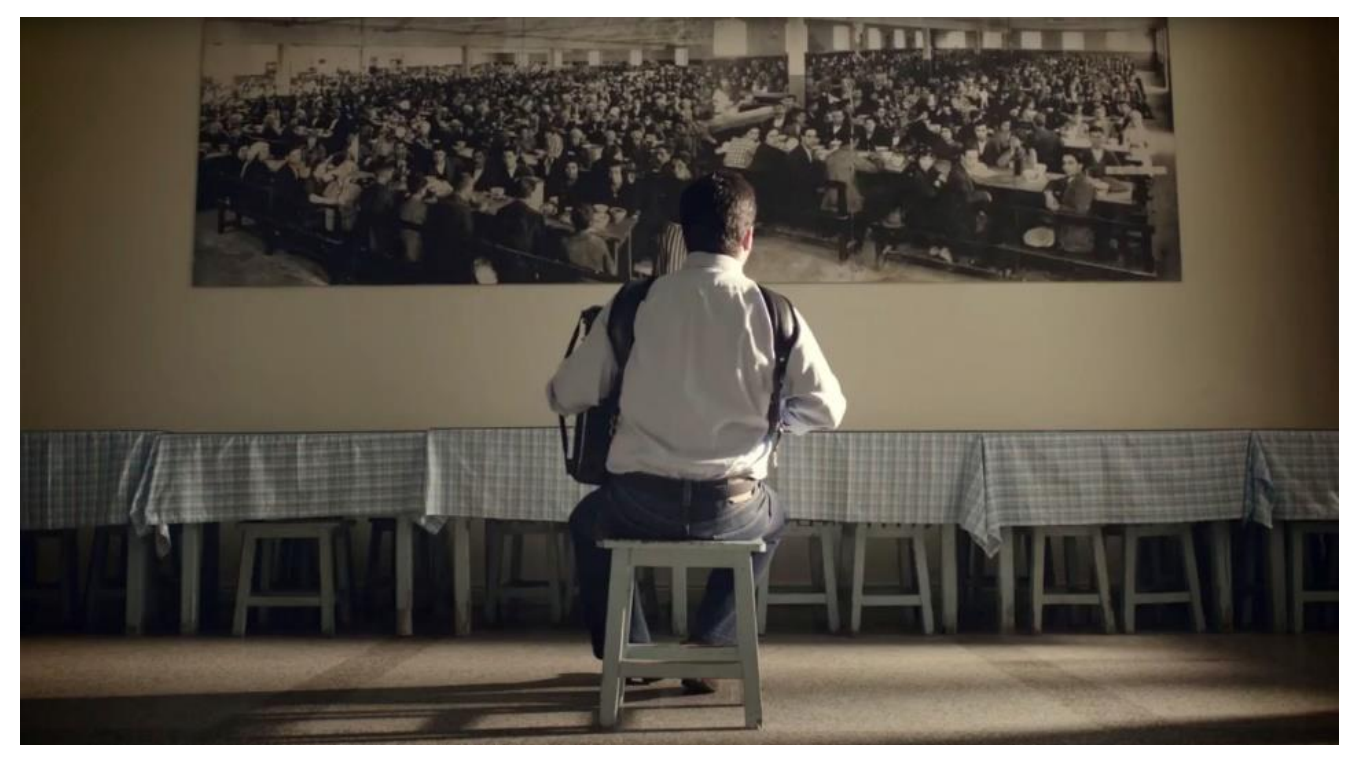

Imagen 4: Fotograma de la película Vidros partidos. Testes para um filme em Portugal de Victor Erice (33m51s).| (c) Guimarães 2012, Capital Europea de la Cultura. 
El primer plano que muestra la fotografía pareciera casi como una toma subjetiva que recorriera esta, una panorámica que nos muestra caras cuyos ojos denotan una historia personal que se suma a una colectiva. ${ }^{4}$ Luego se intercalaran planos fijos más cortos y solo habrá otro en movimiento que muestra a un grupo en concreto, del cual se sacarán después primeros planos. La música, que nos retrotrae al pasado y se ve ilustrada por un montaje de detalles de la fotografía, cambia la tonalidad de los momentos anteriores de la película. Cada personaje, escrupulosamente seleccionado, nos mira interrogándonos, interpelándonos ante todo lo que ya hemos visto a través de las diferentes escrituras cinematográficas, y forman una poética de montaje sobre la realidad. El tiempo que se da a los rostros nos permite tener un momento de contemplación, podemos escudriñar la imagen para cristalizar en estas caras todo lo que antes se ha contado oralmente. Para acabar este bloque, único en el que no es protagonista la palabra, volvemos a través de un encadenado a la mirada de Arménio, que, sin dejar de dirigirse a la fotografía, termina de tocar su acordeón. Tras pasar al plano general con el que empezaba este bloque final aparece un título que dedica la obra fílmica a los hombres y mujeres que trabajaron en la fábrica entre 1845 y 2002.

Con la culminación de esta última parte, asistimos al cierre de la poética de montaje que despliega la película. En este caso vemos que el final es la parte más clásica como unidad tonal emocional de edición, ya que empieza y acaba del mismo modo, recurriendo al plano/contraplano clásico, que después es subvertido por el montaje de los rostros, que más bien miran al espectador. Este es el gesto creativo que se elige para dar un espacio de comprensión personal, meditativo, de todo lo que hemos estado escuchando y viendo. Cada corte de montaje deja el rastro de la intención de la puesta en mirada, que ya tenía en cuenta el propio rodaje. Ahora podemos ver como si fueran las pinceladas de un pintor, las diferentes marcas que se han ido dejando y que quedan simbolizadas en la contemplación de este montaje sobre reencuadres de una fotografía.

El repertorio de elementos de esta última parte suma a los ya vistos la música, convertida en un estrato vertical de montaje que nos coloca en

\footnotetext{
${ }^{4}$ La materialidad de la imagen fotografiada ya estaba en la fotografía de otra obra dirigida por Erice, Alumbramiento. En este caso nos remitía al pasado colonial de una familia española que poseía una tienda en la Habana.
} 
disposición de viajar al pasado, pero con cierto escepticismo. Ahora la mirada del espectador no es del todo cómoda, influida por las palabras anteriormente escuchadas, potenciado por la melancolía que provoca la melodía, evocando la saudade portuguesa. El repertorio de elementos de esta parte combina algunos anteriores, pero añade la frontera entre pasado y presente del personaje y la música, lo cual dispone de una nueva materialidad que texturiza en los rostros de un contexto político y social en cambio, cuyo contrapunto histórico es la mirada del acordeonista y cuya síntesis es el sonido de su instrumento, que hila toda la secuencia.

\section{Conclusión}

En el cine las poéticas nuevas se construyen, comúnmente, en una crítica estética a otras poéticas ya establecidas. El ritmo de montaje favorece la contemplación y la reflexión sobre lo que nos cuentan los personajes. Además, el trabajo de montaje huye de la convención de cualquier formato periodístico. Así, al utilizar la escritura de un guion, los planos de entrevista son más certeros con lo que se quiere comunicar.

Carmen Arocena veía en el cine de Erice un camino recorrido desde el realismo crítico hacia el realismo poético (Arocena 1996, 23), pero en Vidros partidos se da una escritura fílmica dialéctica entre estos dos realismos, desplegada a través de las estructuras de montaje. Se ponen en juego las posibilidades descriptivas de la realidad de las estrategias de edición del documental, pero se potencian procesos de evocación a través del ritmo, del uso del distanciamiento y de la apertura a la contemplación. En consecuencia, podríamos hablar de "cine de noficción”, espacio que se coloca entre los géneros fílmicos tradicionales. Erice ya lo había escrito en 1962: "la forma significa una actitud moral, pero el estilo estará siempre condicionado por las ideas que se manejan" (Erice 1962).

Estos modos de hacer creativo del montaje responden también a un encuentro entre una poética repertorial y otra disposicional. Por una parte, el montaje juega con recursos del reportaje y del documental clásico como la entrevista o los títulos aclaratorios, y, por otro, esa transgresión con el uso de los planos largos en una misma composición para todos los personajes o la ausencia de recursos, para al final hacer un montaje recortando la fotografía en fragmentos que no han ilustrado 
los parlamentos, sino que ahora nos dan la libertad de ser interpretados. Una estructura que nos señala primero la vida de las personas, luego la fotografía que interpela y después el análisis tras el fundido en negro.

Así, el montaje favorece la confluencia entre la realidad poética y la realidad crítica que encarna una estética docuficcional. Esta idea de interpretación en los «entrevistados» permite un ritmo de actuaciones calculado. Es cierto, como apunta de forma muy precisa MoreirasMenor, que esta película podría incluirse dentro de una serie de obras definidas por su tendencia a "una política de la memoria" (MoreirasMenor 2017, 273). Sin embargo, lo que tiene de singular Vidros partidos es que hace una radiografía de la memoria de un grupo social de una forma precisa, con una escritura cinematográfica de montaje que va sumando prismas con diferentes esquemas formales a la visión del tema y que organiza una visión completa en su discurso. La película ha jugado con sencillos elementos de puesta en mirada para darnos las dimensiones precisas sobre la memoria desde una poética propia: diferentes personajes en relación con la fábrica, la fotografía como fondo, la mirada de los "entrevistados". En definitiva, agotar el tema en sus posibilidades expresivas, para ser preciso en la escritura fílmica. Una de las características más importantes de esta poética del montaje es que permite que haya un enriquecimiento del espectador en la contemplación. A través del montaje percibimos esa noción que Marx tenía del arte cuando lo definía como una educación social de los sentidos (Dias Branco 2020, 55). Vamos entrando en las diferentes partes, con sus diferentes propuestas, construyendo el puzzle del capitalismo cognitivo, pero desde una mirada local y una reflexión que requiere de nuestra participación. Emerge una práctica artística comprometida con las personas y con su historia, con su contexto sociopolítico. Hay un claro respeto por lo que se cuenta y por quién lo cuenta. Erice, ya en su labor crítica, destacaba el carácter contextual de cada obra de arte, hecho que al mismo tiempo ha trasladado a la realización de Vidros partidos: "Las obras no se pueden juzgar sin situarlas en su contexto real. Y situarlas quiere decir conocer por completo ese contexto" (Erice 1962).

El montaje, en el caso por ejemplo de los primeros planos, favorece la empatía y la expresión de las emociones que provoca el recuerdo. En este sentido, se hacen muy relevantes las referencias a historias personales, a testimonios experienciales verdaderos, que están 
colocados en el montaje de tal forma que vamos profundizando en el pasado de la fábrica y su vinculación con el presente: la vida en la fábrica, la mirada hacia la fotografía, el arte que mira a la vida del capitalismo industrial, la herencia emocional-histórica-social y la estética de una fotografía desde el conocimiento. Todo esto puede resumir el encuentro poético/crítico con la realidad.

No podemos olvidar el uso de la música, ya que nos recuerda esa clara fragmentación en partes que remiten en nuestro análisis a una diferenciación de unidades tonales emocionales que en su conjunto crean una tonalidad total, ya que la música cumple una función diegética para prefigurar un contacto entre pasado y presente. Así, entendemos la poética del montaje de Vidros partidos como una antropomorfización a través de diferentes unidades tonales puestas en relación y desplegadas en los estratos materiales que componen la textura fílmica. Esta textura queda definida dentro de un "cine de no ficción”, cuya baza estructural de montaje está ya determinada en la puesta en mirada, pero que se cristaliza en la sala de edición. Dicha reantropomorfización de montaje recoge estrategias de reconocimiento de formas tradicionales del cine documental. Sin embargo, son subvertidas en un esfuerzo de agotar el tema de la memoria en su espacio de sensibilidad y desarrollo, dentro de una dialéctica entre el capitalismo industrial y el cognitivo.

\section{Referencias}

Arendt, Hanna. 2005. La condición humana. Barcelona: Paidós.

Arocena, Carmen. 1996. Víctor Erice. Madrid: Cátedra.

Armador, José. 2019. "Vidros partidos de Erice: viaje al interior de una fotografía”. In Código Cine. Acceso 30 enero 2021. https://codigocine.com/vidrios-rotos-victor-erice/.

Aumont, Jacques, Bergala, Alain, Marie, Michel y Vernet, Marc. 1996. Estética del cine. Barcelona: Paidós.

Bergala, Alain. 2007. La hipótesis del cine. Barcelona: Laertes.

Bresson, Robert. 1997. Notas sobre el cinematógrafo. Madrid: Árdora.

Broncano, Fernando. 2019. Puntos ciegos. Ignorancia pública y conocimiento privado. Madrid: Lengua de Trapo. 
Bruno, Giuliana. 2014. Surface: Matters of Aesthetics, Materiality, and Media. Chicago, IL.: University of Chicago.

Claramonte, Jordi. 2016. Estética modal. Madrid: Tecnos.

Cucinotta, Caterina. 2018. Viagem no cinema através do seu vestuário. Covilhã: LabCom.

Dias Branco, Sergio. 2020. O Trabalho das Imagens. Estudos sobre cinema e marxismo. Lisboa: Página a Página.

Erice, Víctor. 1962. "Responsabilidad y significación estética de una crítica nacional". In Nuestro Cine, ${ }^{\circ}$ 15, Madrid, diciembre 1962. Recuperado por Marienbad. Revista de cine y cultura audiovisual. $\begin{array}{llll}\text { Acceso } & 30 & \text { enero } & \end{array}$ https://www.marienbad.com.ar/documento/victor-ericeresponsabilidad-y-significacion-estetica-de-una-critica-nacional.

Foucault, Michel. 2007. El Nacimiento de la Biopolítica. México: Fondo de Cultura Económica

Hartmann, Nicolai. 1986. Estética. México: Fondo de Cultura Económica.

Lukács, György. 2019a [1958]. "Sobre los problemas estéticos del cinematógrafo”. In No lo saben pero lo hacen. Textos sobre cine y estética de György Lukács, organizado por Jordi Claramonte y Jesús Ramé, 175-192. Madrid: Plaza y Valdés.

. 2019b [1963]. "Problemas generales de la mímesis." In No lo saben pero lo hacen. Textos sobre cine y estética de György Lukács. Organizado por Jesús Raméy Jordi Claramonte, 61-86. Madrid: Plaza y Valdés.

Moreiras-Menor, Cristina. 2017. "Trace and Defamiliarization in Contemporary Documentary (Víctor Erice and Eloy Enciso Cachafeiro)". In Rerouting Galician Studies: multidisciplinary interventions, 269-283. https://doi.org/10.1007/978-3-31965729-5_18

Peralta García, Beatriz. 2017. "Los orígenes del teatro socialista en Portugal: O Capital (1895), de Ernesto da Silva”. História - Revista da FLUP. IV, 7 (2), 216-236. https://doi.org/10.21747/0871164X/hist7_2oe4

Ramé, Jesús y Claramonte, Jordi, (orgs.). 2019. No lo saben pero lo hacen. Textos sobre cine y estética de György Lukács. Madrid: Plaza y Valdés. 
Salles, Cecilia. 1998. Gesto inacabado. Processo de criação artística. São Paulo: FAPESP y Annablume.

Villarmea Álvarez, Iván. 2020. "It could happen to you: Empathy and empowerment in Iberian austerity cinema”. In Cinema of crisis. Film and Contemporary Europe. Austin, organizado por Thomas Austin y Angelos Koutsourakis, 150-163. Edinburgh: Edinburgh University Press.

\section{Filmografia}

Alumbramiento. Dir. Víctor Erice. Producción Nautilus films S.L. y Ruedo producciones, España. 2002. 11 min.

El desencanto. Dir. Jaime Chavarri. Producción Elías Querejeta, España. $1976.97 \mathrm{~min}$.

El espíritu de la colmena. Dir. Víctor Erice. Producción Elías Querejeta, España. 1973. 94 min.

Los Rubios. Dir. Albertina Carri. Producción Pablo Wisznia, Argentina. 2003. $89 \mathrm{~min}$.

Trás-os-Montes. Dir. António Reis y Margarita Cordeiro. Producción Centro Português de Cinema, Radiotelevisão Portuguesa y Tobis, Portugal. 1976. 108 min.

Vidros partidos. Dir. Víctor Erice. Producción Nautilus Films S.L., Portugal. 2012. $37 \mathrm{~min}$.

\section{Vidros partidos (2012), de Víctor Erice: Uma poética da montagem}

RESUMO Vidros partidos é uma curta-metragem dirigida por Victor Erice que integra o filme de produção portuguesa Centro Histórico (2012). A este projeto (produzido por Guimarães 2012, Capital Europeia da Cultura) juntaram-se os realizadores Pedro Costa, Manoel de Oliveira e Aki Kaurismäki, com curtas-metragens próprias. O filme passa-se numa fábrica do norte de Portugal e parte de uma fotografia de trabalhadores que está pendurada na parede do refeitório. É composto por diferentes entrevistas com pessoas que tiveram alguma relação com a fábrica e que, desse modo, refletem um contexto de produção que o capitalismo cognitivo fez desaparecer. No entanto, o guião é assinado pelo autor e intervém um ator profissional, o que faz colapsar a ideia de que estamos perante um documentário. A verdade do filme deve ser encontrada 
noutro espaço da obra, entre a ficção e o documentário. Tudo isto é acompanhado de uma proposta de montagem que tenta desvendar os segredos da fotografia que dá origem ao filme. A partir da estética dos materiais, investigaremos qual é o gesto criativo da montagem no processo criativo que se cristaliza numa textura fílmica. Concentrar-nos-emos nos modos de relação que se geram entre os materiais organizados em unidades tonais em suas diferentes partes para, assim, criar uma unidade total de discurso. A montagem de Vidros partidos, após a escrita precisa do guião e da filmagem, implica, nos termos de Lukács, uma re-antropomorfização acionada pelo ritmo fílmico, que deixa um traço da sua génese artística e expressa uma poética que explica a transição do capitalismo industrial para o capitalismo cognitivo.

PALAVRAS-CHAVE Estética cinematográfica; teoria da montagem; documentário; Víctor Erice; materialidades; processos criativos.

\section{Víctor Erice's Vidros partidos (2012): A montage poetics}

ABSTRACT Vidros partidos is a short film directed by Víctor Erice that is part of the Portuguese-produced film Centro Histórico (2012). This project (produced by Guimarães 2012, Cultural Capital of Europe) was joined by the directors Pedro Costa, Manoel de Oliveira and Aki Kaurismäki, with their own short films. The film takes place in a factory in northern Portugal and starts from a photograph of workers that hangs on a wall in its refectory. It is composed of different interviews with people who had some relationship with the factory, reflecting a production context that cognitive capitalism has made disappear. The script is signed by the author and includes the intervention of a professional actor, thus collapsing the idea that this is a 'pure' documentary. The truth of the film must therefore be found elsewhere, between fiction and documentary. All this is accompanied by a montage proposal that tries to unravel the secrets of the photography that gives rise to the film. Adopting the point of view of the aesthetics of the materials, we will investigate the creative gesture of montage in the creative process that crystallizes in a filmic texture. We will focus on the modes of relationship that are generated between the materials organized in tonal units in their different parts so as tocreate a total unit of discourse. The montage of Vidros partidos, after the precise writing of the script and the filming, entails, in Lukács's terms, a re-antropomorphization brought into play by the filmic rhythm, which leaves a trace of its artistic genesis and thus expresses a poetics that allows for the emergence of an explanation about the transition from industrial to cognitive capitalism.

KEYWORDS Film aesthetic; film montage theory; documentary; Víctor Erice; materialities; creative processes.

Recebido a 31-01-2021. Aceite para publicação a 18-4-2021. 